\title{
Study on Medium Voltage Energy Loss due to Interconnection of Embedded Generation to the Distribution Network
}

\author{
GN Alahakoon \\ Ceylon Electricity Board
}

\begin{abstract}
This paper presents the impact on the distribution line losses due to embedded generation. Studies were performed using SynerGEE simulation model on the selected feeders, where significant Embedded Generations (EG) are connected. Initially, a study was conducted assuming a hypothetical feeder with constant load and different level of EG capacity. It is seen that depending on the location of the load along the feeder and the EG capacity, the losses on the feeder will vary. Hence an attempt was made to identify the optimum EG capacity that will result in minimum allowable loss on a feeder. Thereafter, studies were performed on actual feeders with load variation and EG capacity variation. Daily load pattern for each feeder was assumed to be similar, but actual maximum demands were measured feeder wise. Historical monthly Plant Factor (PF) data was analyzed and used in actual simulation studies. It is concluded that excessive losses occur during low load condition and also during higher generation from EGs. Hence, appropriate measures are required in the longer term to absorb higher generation from EGs to minimize the losses in the distribution feeders.
\end{abstract}

\section{Introduction}

Ceylon Electricity Board allowed the development of embedded generation in mid 1990s, mainly private mini hydro power plants, whose installed capacity is less than 10 MW. At present there are around 140 power plants with an installed capacity of 290MW, located in the hill country. All the embedded generation is governed by the Standardized Power Purchase Agreement (SPPA) and energy is purchased through a standardised tariff.

One of the main objectives of developing Embedded Generation is to promote the renewable energy contribution to the national grid in accordance with the government policy. During the past two decades, several major power plants were commissioned and to analyze the impact on the distribution system loss, a case study was carried out on selected feeders in the Ratnapura Grid Substation (GS).

It is observed that in certain feeders of the Ratnapura GS, the power flow is negative, because the generation from the minihydros are greater than the local loads, which results in negative power flow. That is, power flows from the feeder towards the GS and flows back into the transmission system. In order to analyze the impact of such generation on the distribution losses, feeders attached to Ratnapura GS were selected for further analysis.

\section{Theoretical Analysis}

Hypothetical analyses was carried out to visualize the distribution line losses with respect to the location of the load along the feeder and the EG was fixed at the end of the feeder.

For this analysis, a $20 \mathrm{~km}$ long single circuit line with Lynx conductor consisting 10MW constant spot load was considered, which is fed by a GS and also by an EG. Simulations were carried out using the SynerGEE model.

In order to analyze the loss variation in respect of both feeder load and amount of generation, a ratio was defined, that is percentage of feeder load with respect to the mini hydro generation. (Feeder Load/Embedded Generation “L/EG”).

In this analysis, location of the load along the feeder was moved from GS end to the EG end by keeping the ratio between Demand and Embedded Generation (L/EG) constant.(Refer Figure 1). Thereafter, the same analysis was carried out for different " $\mathrm{L} / \mathrm{EG}$ " ratios to calculate the distribution line loss reduction as a percentage of EG output. 
Figure 1 - Typical Arrangement of Load and EG

\begin{tabular}{|c|c|c|c|c|c|}
\hline \multirow[t]{2}{*}{ GS } & & & & & \\
\hline & $5 \mathrm{~km}$ & $10 \mathrm{~km}$ & $15 \mathrm{~km}$ & $20 \mathrm{~km}$ & T. \\
\hline
\end{tabular}

The study was performed for "L/EG" ratios for 1, 0.5 and 2.0 and the line loss variation is shown in Figure 2. Figure 3 shows the line loss reduction compared with the case where there is no EG. Figure 4 shows the line loss reduction as a percentage to EG value.

\section{Figure 2 - Line Loss Vs Location of Demand} from the GS

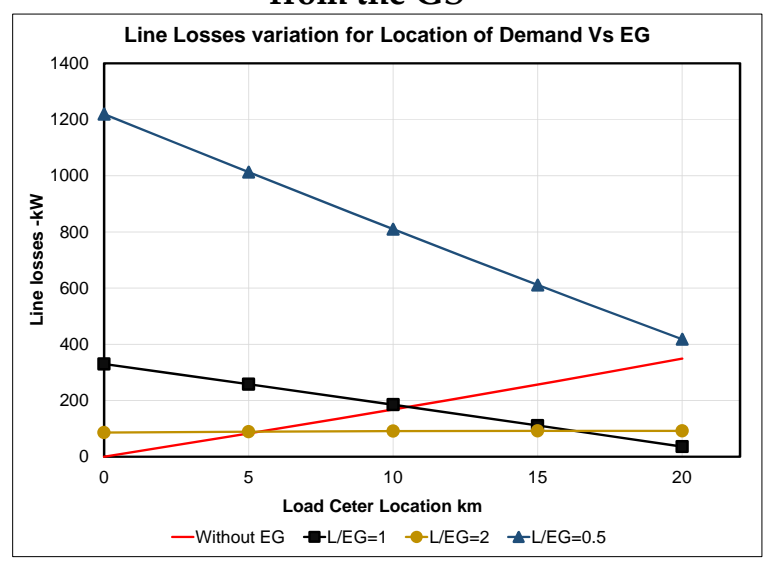

Figure 3 - Line Loss Reduction Vs Load Centre

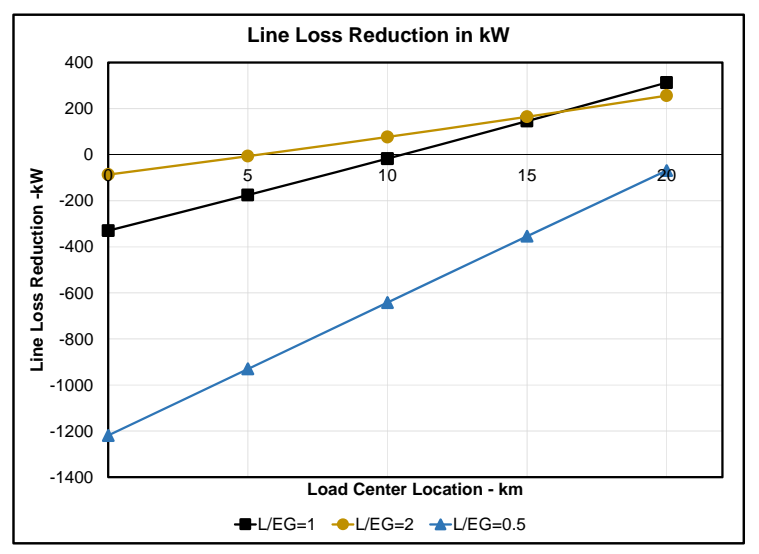

Figure 4 - Loss Reduction as a Percentage of EG Output

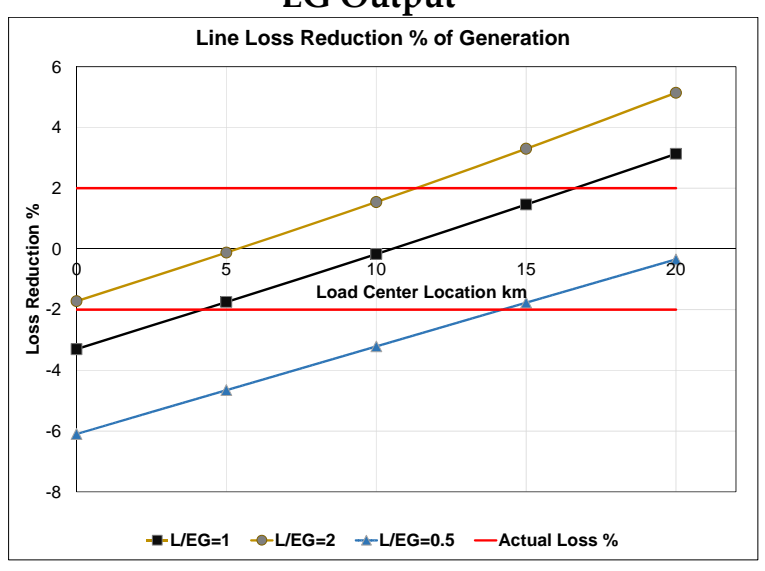

Distribution losses would be minimum if the EG is closer to the load centers.

- $\quad$ From the above analysis, the following could be perceived.

- $\mathrm{L} / \mathrm{EG}$ ratio $\geq 1$ to minimize the cumulative line losses,

- Excess EGs, that is higher than the feeder load, would result in increased distribution line losses,

- Optimum EG capacity will depend on existing locations of load centers, their load levels and geographical locations of EGs.

Other issues such as voltage rise due to excessive EG are not considered in this analysis.

However, above hypothetical analysis is different from the practical scenario. In actual situation, the daily demand on a feeder varies with the time. That is, during off-peak time, the demand on the feeder is very low. Furthermore, actual generation from EG varies depending on the rainfall. In addition geographical distribution of loads along the feeder and EG necessitates that such analysis be carried out using computer aided models, and in this case SynerGEE model was used. 


\section{Data Requirement for Actual Analysis}

As the demand on the feeder varies over the day, it is required to obtain the feeder wise hourly load data. Furthermore, depending on the EG output, the measured feeder load at the GS varies. Therefore, it is required to gather information on the generation pattern of the EGs connected to that feeder. Once these information is gathered, using the SynerGEE model, losses on the selected feeder could be estimated for various load conditions and also for different levels of EG output.

\section{Assessment of Feeder Load}

In order to access the feeder load, it was assumed that the feeder loading varies similar to the daily demand curve shape of Sri Lanka. Based on this hypothesis, feeder load was divided into one hour blocks as a percentage of peak demand and is graphically is shown in Figure 5, and Figure 6 shows the load duration curve.

\section{Figure 5 - Typical Daily Demand Curve of} the Feeder

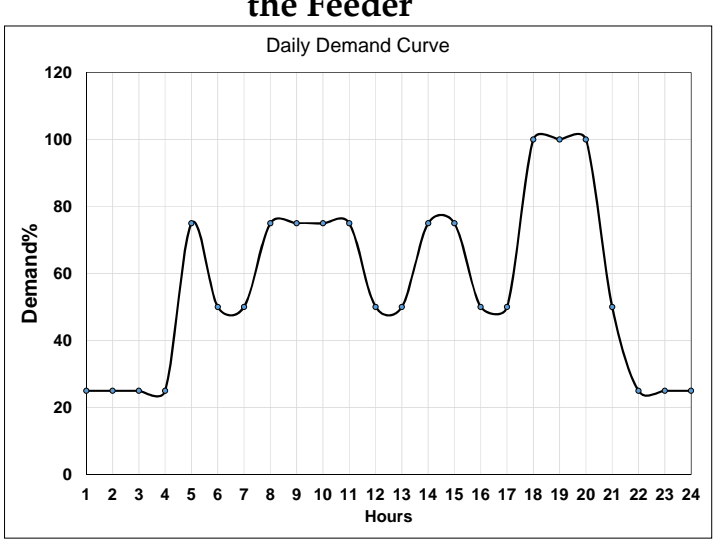

Figure 6 - Load Duration Curve

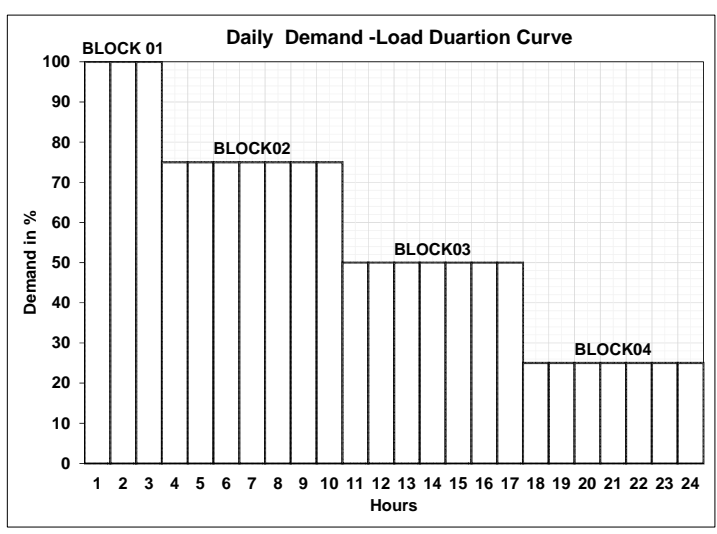

\section{Assessment of Mini Hydro Generation}

Since all the EGs connected to Ratnapura GS are miniydro plants (MHP), monthly plant factors (PF) of EGs were estimated by considering the actual monthly generation for the year 2014. Therefore, monthly plant factor (PF) of EGs were calculated considering the actual MHP generation of year 2104 and average PF was $70 \%$, even during heavy rainy periods. Actual PFs of MHPs connected to Ratnapura GS were considered for the analysis in order to calculate the line losses.

\section{Methodology}

Initially the losses were calculated considering the developed daily demand curve in Figure 5 for each feeder, without EGs. Thereafter, feeder losses were re-calculated by considering the monthly PFs of each feeder. Finally, distribution line loss reduction due to addition of EGs were derived for different PFs and the optimum EG capacity was derived which will minimize the loss on the selected feeder.

\section{Case Study}

Ratnapura Eheliyagoda Feeder (F03)

Three MHPs of 12.25MW are already connected to Feeder 03 and two other MHPs of 2.4MW are proposed to be connected. Loss analysis was carried out for PFs with $15 \%$, $25 \%, 40 \%, 60 \%$ and $70 \%$, considering monthly power factors of commissioned MHPs of this feeder.

\section{Figure 7 - Plant Factors of EGs during the Year}

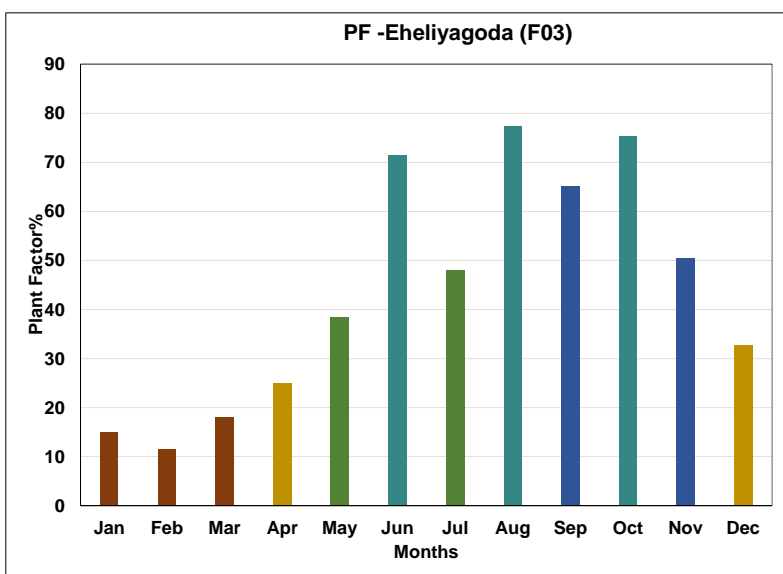


Table 1 - Seasonal Plant Factor of EG

\begin{tabular}{|l|c|c|c|c|c|}
\hline $\begin{array}{l}\text { Plant } \\
\text { Factors }\end{array}$ & $\mathbf{1 5 \%}$ & $\mathbf{2 5 \%}$ & $\mathbf{4 0} \%$ & $\mathbf{6 0} \%$ & $\mathbf{7 0} \%$ \\
\hline \multirow{3}{*}{ Months } & Jan & April & May & Sep & June \\
\cline { 2 - 6 } & Feb & Dec & July & Nov & Aug \\
\cline { 2 - 6 } & Mar & & & & Oct \\
\hline
\end{tabular}

Accordingly to the MV development plan in year 2014, the recorded peak demand has been 8.813 MVA for the Ratnapura-Eheliyagoda feeder, while total capacity of 12.25 MW MHP remained connected to it. Consequently "L/EG" ratio for the above feeder was about $72 \%$.
However, recorded maximum PF was about $70 \%$ even during the rainy season and L/EG ratio increases to $102 \%$.

Within these months, EG power flow would be towards the grid with higher distribution losses. In accordance with the hypothetical analysis, "L/EG" ratio should be $\geq$ $100 \%$.SynerGEE simulations were carried out for each load block and for each PF. The results for $70 \% \mathrm{PF}$ for each block is shown in Table 2.

Table 2 - Losses at Varying Load Levels

\begin{tabular}{|c|c|c|c|c|c|c|c|c|c|}
\hline & \multirow{3}{*}{\multicolumn{2}{|c|}{ Without MHPs }} & \multirow{2}{*}{\multicolumn{4}{|c|}{ Plant Factor- 70\% }} & \multirow[b]{4}{*}{\begin{tabular}{|l|} 
Loss \\
Reduction \\
(kW)
\end{tabular}} & \multirow[b]{4}{*}{\begin{tabular}{|l|} 
Loss \\
Reduction \\
with \\
respect to \\
EG (\%) \\
\end{tabular}} \\
\hline & & & & & & & & & \\
\hline & & & & \multicolumn{4}{|c|}{ With MHPs } & & \\
\hline $\begin{array}{l}\text { Demand } \\
\text { Blocks }\end{array}$ & \begin{tabular}{|l|} 
Load \\
Variation \\
of the \\
Feeder
\end{tabular} & $\begin{array}{l}\text { Load [L] } \\
\text { Amps (A) }\end{array}$ & $\begin{array}{l}\text { Loss } \\
\text { (kW) }\end{array}$ & $\begin{array}{l}\text { Generation - } \\
\text { [EG] (Amps) }\end{array}$ & L/EG \% & $\begin{array}{l}\text { Grid net Load } \\
\text { Amps (A) }\end{array}$ & Loss (kW) & & \\
\hline Block 04 & 0.25 & 92 & 36 & 154 & 59.7 & 64 & 269 & -233 & -2.72 \\
\hline Block 03 & 0.5 & 113 & 71 & 154 & 73.4 & 46 & 262 & -191 & -2.23 \\
\hline Block 02 & 0.7 & 133 & 118 & 154 & 86.4 & 30 & 268 & -150 & -1.75 \\
\hline Block 01 & 1 & 154 & 179 & 154 & 100.0 & 24 & 285 & -106 & -1.24 \\
\hline & & & & & our $A$ & ged Loss re & ncreament & -180.67 & -2.11 \\
\hline
\end{tabular}

Similarly the above analysis was repeated for other PFs, i.e. $60 \%, 40 \%, 25 \%$ and $15 \%$.

The results of the simulations are shown in figure 9 , i.e. the loss variation with respect to "L/EG".

\section{Figure 9 - Loss Reduction as a \% of EGs}

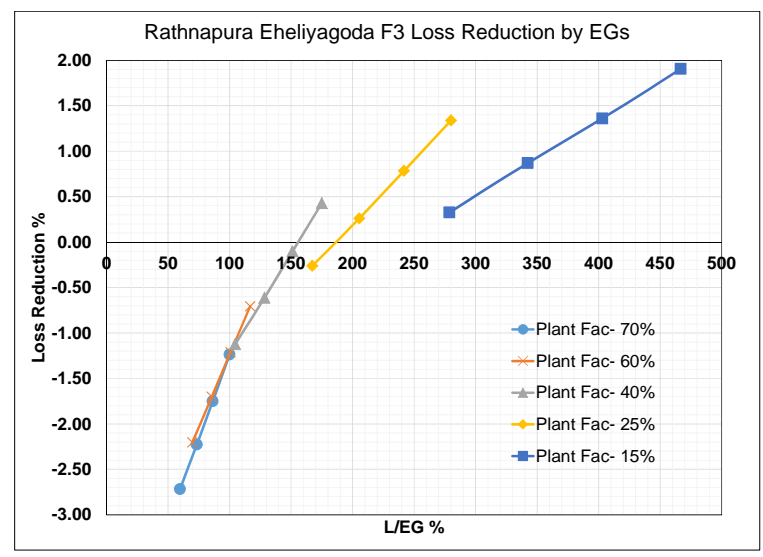

The figure 9 shows that the embedded generation capacity that would result the minimum loss in the selected feeder, when "L/EG" ratio of around $175 \%$. Cumulative losses per annum with respect to daily demand curve and PF is graphically shown in Figure 10.

\section{Figure 10 - Cumulative Energy Loss}

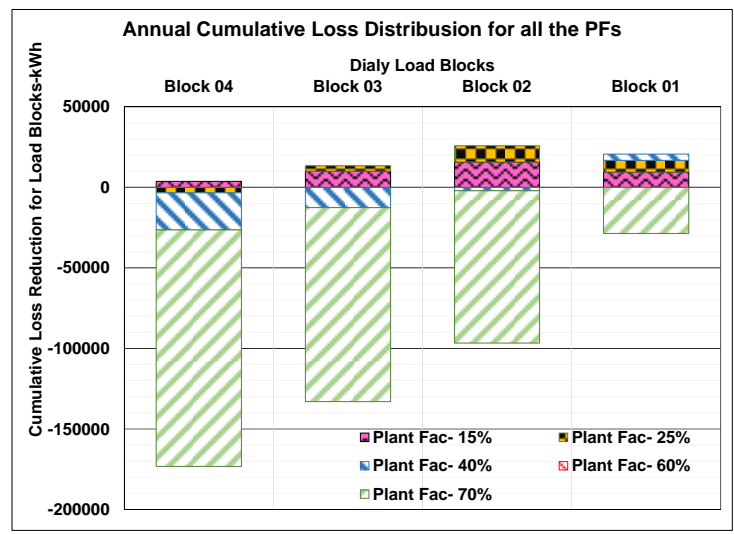

Figure 10 shows that the annual line loss increases due to addition of EGs, which is beyond the optimum EG value. In most cases, "L/EG" $<100 \%$. The Standard Power Purchase Agreement (SPPA) stipulates that the metering point of EG shall be within the EG premises. Hence, medium voltage line losses due to addition of EGs is not accounted and it has to be borne by the purchaser, the Ceylon 
Electricity Board, and its cost passed on to customers.

The average price paid to MHPs is around Rs.14.25 per kWh for the year 2014, and annual line loss due to EGs in above feeder is estimated as LKR 7.6 million. Estimated annual energy loss reduction was around $535,020 \mathrm{kWh}$.This methodology was repeated for other feeders at Ratnapura GS with EGs.

\section{Ratnapura Durekanda Feeder (F08)}

Figure 11 - Loss Reduction as a \% of EGs

\begin{tabular}{|l|l|l|l|l|l|}
\hline \multicolumn{5}{|c|}{ Rathnapura - Durekanda F08 } \\
\cline { 2 - 6 } & & & & \\
\hline \\
\hline
\end{tabular}

The "L/EG" ratio for F08was around $145 \%$ and annual loss due to EG is LKR 8.4 million. Estimated annual energy loss reduction was around $-589,620 \mathrm{kWh}$.

\section{Ratnapura Kuruwita (F05)}

Figure 12 - Loss Reduction as a \% of EGs

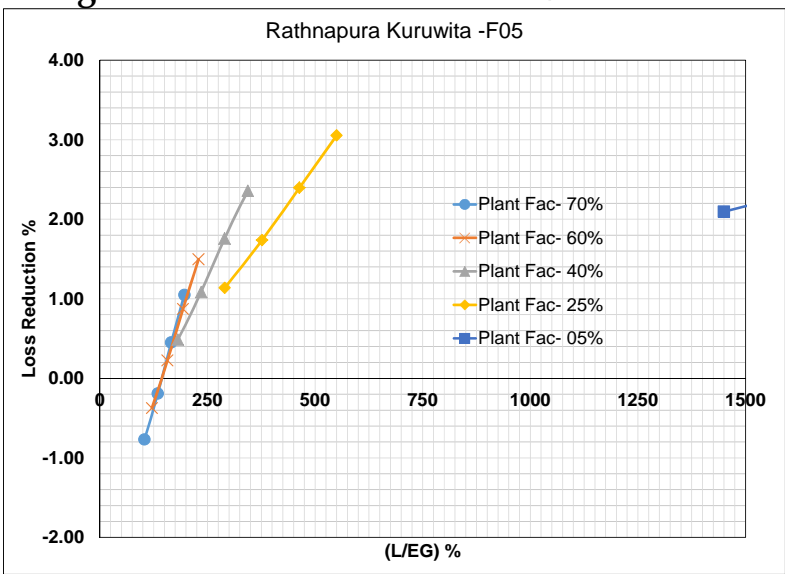

The "L/EG" ratio for F05 was around 145\% respective annual loss reduction due to EG was LKR 2.3 million. Estimated annual energy loss reduction is around $160,170 \mathrm{kWh}$ per annum.

\section{Ratnapura Nivithigala (F06)}

Figure 13 - Loss Reduction as a \% of EGs

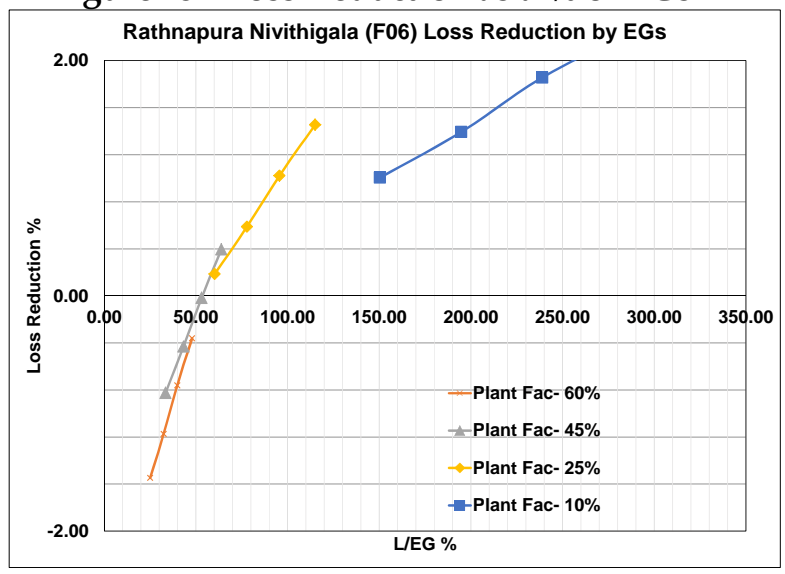

In this feeder almost 9MW generation out of 12.25 MW is located near Ratnapura GS. , but the customer load is distributed among the feeder. Hence, excess power from EGs will flow to the GS with minimum line length and results in lower line losses. "L/EG" ratio for this feeder was $55 \%$ and respective annual loss reduction due to EG was LKR 0.8 million. Estimated annual energy loss reduction is around 57,030kWh.

The other four feeders of the Ratnapura GS do not have any commissioned EGs yet.

\section{Cumulative Summary of Line Losses}

As seen in the above analysis, the total loss reduction in $33 \mathrm{kV}$ feeders due to $\mathrm{EG}$ are summarized in Table 3.

Table 3 - Summary of Losses Reduced

\begin{tabular}{|l|r|r|r|}
\hline \multicolumn{1}{|c|}{ Feeder Name } & $\begin{array}{c}\text { Annual Average } \\
\text { Plant Factor }\end{array}$ & $\begin{array}{r}\text { Annual Line Loss } \\
\text { Reduction in kWh }\end{array}$ & $\begin{array}{c}\text { Estimated Cost } \\
\text { in Rs. }\end{array}$ \\
\hline $\begin{array}{l}\text { Rathnapura -Eheliyagoda } \\
\text { Feeder (F03) }\end{array}$ & 42.08 & $-535,020$ & $-7,624,035$ \\
\hline $\begin{array}{l}\text { Rathnapura Durekanda } \\
\text { Feeder (F08) }\end{array}$ & 41.25 & $-589,620$ & $-8,402,085$ \\
\hline $\begin{array}{l}\text { Rathnapura Kuruwita } \\
\text { Feeder(F05) }\end{array}$ & 38.33 & 160,170 & $2,282,423$ \\
\hline $\begin{array}{l}\text { Rathnapura Nivithigala } \\
\text { Feeder(F06) }\end{array}$ & 27.92 & 57,030 & 812,678 \\
\hline Total Loss Reduction & & $\mathbf{- 9 0 7 , 4 4 0}$ & $\mathbf{- 1 2 , 9 3 1 , 0 2 0}$ \\
\hline
\end{tabular}

The analysis figure out that, line losses will further increase with the addition of new EGs and plant factors of commissioned EGs. Further, MHPs operate at its maximum capacity during rainy seasons, where larger reservoirs are also at their spill levels. Actual energy sent out from Ratnapura GS in the year 2014 was - 29,602.00 MWh. Figure 14 shows the monthly energy flow through GS in year 2014. 
Figure 14 - Actual Energy Sent out from Ratnapura GS in year 2014

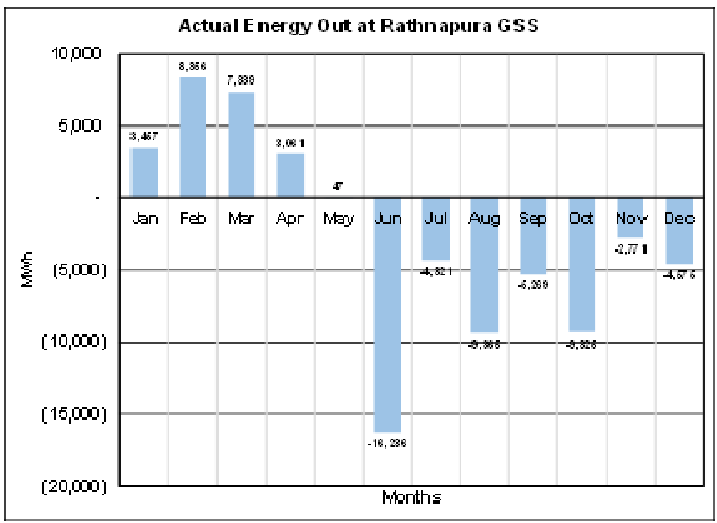

Figure 14 shows that, in most cases demand in Ratnapura GS is less than the generation of EG. Hence, in the actual situations "L/EG" $<100 \%$ and results in higher distribution line losses in MV feeders.

\section{Conclusion}

The impact of EG on distribution line losses have been analyzed for variable daily demand and minihydro penetration levels. In actual situations, "L/EG" ratio will fluctuate with the load variation, load dispersion, geographical dispersion of EG, and EG's plant factors. Most of the EGs are generally located in remote areas, that is, in rural areas where the customer demand is very low. Further, EGs are located generally at feeder ends and not at load centers. In such cases, it could be concluded that L/EG ratio requires to be more than $100 \%$ to minimise the distribution line losses.

Excess penetration of EGs will lead to higher line losses as well as voltage rise at off-peak times. In order to develop a good plan for EG development, detailed studies need to be carried out taking into account the demand distribution, location of proposed EGs and the feasibility of storing excess energy during offpeak hours and to utilize them during peak hours. Therefore, existing mini hydro plants have to be converted to hybrid plants in the longer term with suitable energy storing methods, which could enhance the excess penetration of EG to the distribution network.

Note: This paper was presented in the Energy Symposium Sri Lanka 2015.

\section{References}

[1] "Integration of Non-Conventional Renewable Energy Based Generation into Sri Lanka Power Grid"- 2015, Study Team, CEB.

[2] "System Control \& Operations" Reports in year 2014 by System Control Branch, Ceylon Electricity Board.

[3] "Power Purchased from small power producers" reports in year 2014 by Energy Purchase Branch, CEB. 